\title{
Comparison of Road Traffic Noise Prediction Models: CNOSSOS-EU, Nord2000 and TRANEX
}

Jibran Khan ${ }^{1,2, *}$, Matthias Ketzel ${ }^{1,3}$, Steen Solvang Jensen ${ }^{1}$, John Gulliver ${ }^{4}$, Erik Thysell ${ }^{5}$, Ole Hertel ${ }^{1,2}$

${ }^{1}$ Department of Environmental Science, Aarhus University, Roskilde, Denmark

${ }^{2}$ Danish Big Data Centre for Environment and Health (BERTHA) at Aarhus University, Roskilde, Denmark

${ }^{3}$ Global Centre for Clean Air Research (GCARE), Department of Civil and Environmental Engineering,

University of Surrey, Guildford, United Kingdom

${ }^{4}$ Centre for Environmental Health and Sustainability, School of Geography, Geology and the Environment,

University of Leicester, Leicester, United Kingdom

${ }^{5}$ FORCE Technology, Hørsholm, Denmark

\section{Abstract}

Road traffic noise is the most pervasive source of ambient outdoor noise pollution in Europe. Traffic noise prediction models vary in parameterisation and therefore may produce different estimates of noise levels depending on the geographical setting in terms of emissions sources and propagation field. This paper compares three such models: the European standard, Common Noise Assessment Methods for the EU Member States (hereafter, CNOSSOS), Nord2000 and Traffic Noise Exposure (TRANEX) model based on the UK methodology, in terms of their source and propagation characteristics. The tools are also compared by analysing estimated noise $\left(\mathrm{L}_{\text {Aeq }}\right)$ from CNOSSOS, Nord2000 (2006 version), and TRANEX for more than one hundred test cases $(\mathrm{N}=111)$ covering a variety of source and receiver configurations (e.g. varying source to receiver distance). The main aim of this approach was to investigate the potential pattern in differences between models' performance for certain types of configurations. Discrepancies in performance may thus be linked to the differences in parameterisations of the CNOSSOS, Nord2000, and TRANEX (e.g. handling of diffraction, refraction). In most cases, both CNOSSOS and TRANEX reproduced $\mathrm{L}_{\text {Aeq }}$ levels of Nord2000 (2006 version) within three to five dBA (CNOSSOS: 87\%, TRANEX: $94 \%$ ). The differences in $\mathrm{L}_{\text {Aeq }}$ levels of CNOSSOS, compared to Nord2000, can be related to several shortcomings of the existing CNOSSOS algorithms (e.g. ground 
attenuation, multiple diffractions, and mean ground plane). The analyses show that more research is required in order to improve CNOSSOS for its implementation in the EU. In this context, amendments for CNOSSOS proposed by an EU Working Group hold significant potential. Overall, both CNOSSOS and TRANEX produced similar results, with TRANEX reproducing Nord2000 $\mathrm{L}_{\text {Aeq }}$ values slightly better than the CNOSSOS. The lack of measured noise data highlights one of the significant limitations of this study and needs to be addressed in future work.

Keywords: Traffic noise, CNOSSOS, Nord2000, TRANEX, noise modelling.

\section{List of abbreviations/acronyms}

AADT, Annual average daily traffic; BioSHARE, Biobank Standardization and Harmonization for Research Excellence in the European Union; CNOSSOS, Common Noise Assessment Methods for the EU Member States; CoRTN, Calculation of Road Traffic Noise; Danish EPA, Danish Environmental Protection Agency; DAC, Dense Asphalt Concrete; EC, European Commission; EEA, European Environmental Agency; EU, European Union; GIS, Geographic Information Systems; HDV, Heavy-duty vehicle; LDV, Light-duty vehicle; $L_{\text {den, }}$ Day-evening-night $A$-weighted equivalent continuous noise level with $5 \mathrm{dBA}$ penalty for evening-time noise and $10 \mathrm{dBA}$ penalty for night-time noise; $\mathrm{L}_{\text {Aeq,oh - Laeq,23h, }}$ Hourly A-weighted equivalent continuous noise levels; $L_{\text {Aeq, }} 24$ hours A-weighted equivalent continuous noise level; MDV, Medium-duty vehicle; N2kR, Nord2000 Road; R, Receiver; S, Source (noise source); S - R distance, Source to receiver distance; SMA, Stone Mastic Asphalt; SPL, Sound pressure level; WHO, World Health Organization.

*Corresponding author at Jibran Khan, Department of Environmental Science, Aarhus University, DK-4000, Roskilde, Denmark. E-mail: jibran@envs.au.dk, Phone: +4587158671.

\section{Introduction}


Noise remains a major environmental problem in Europe. It is the second most harmful environmental stressor, after fine particulate matter, concerning adverse health effects and well-being (WHO, 2019). According to the European Environment Agency (EEA, 2020), approximately 82 million people are exposed daily to harmful levels of roadway noise $\left(L_{\text {den }} \geq 55 \mathrm{~dB}\right)$ inside urban areas. Long-lasting exposure to noise increases the risk of adverse health effects like ischaemic heart disease (Sørensen et al., 2012; Van Kempen et al., 2018) and premature death (Khomenko et al., 2020). In conjunction, the societal cost of the roadway noise, in terms of direct costs and externalities (medical treatment, reduced productivity at work, etc.), is estimated to be 40 billion euros per year in the EU (Navrud, 2002; Van Essen et al., 2011).

Assessing noise pollution is essential for environmental managers in local city authorities for noise abatement and control (Garg and Maji, 2014; EEA, 2018). Presently, several state-of-the-art noise prediction models are in use. The majority of these models incorporate source emission and propagation modules to predict noise levels. In such models, traffic is considered as point or line sources in the calculation of the propagation of sound from the source to the receiver. The comparison of source and propagation characteristics of the different models provides insights into their agreement and disagreement (Garg and Maji, 2014; de Lisle, 2016).

In Denmark, noise is usually predicted using the Nord2000 model (The Danish EPA, 2006, 2020; Kragh et al., 2006; Kragh, 2009a), one of the Nordic noise prediction standards, and the Danish EPA's "prescribed" calculation method for road noise (e.g. Sørensen et al., 2014). Another technique, Road Traffic Noise 1996 (RTN-96) (Jonasson and Nielsen, 1996; Bendtsen, 1999), is also used, which is not included in the present comparison study. Also, according to the annexe II of the Environmental Noise Directives (END) (The European Commission, 2015), as of 31 December 2018, it is mandatory to use CNOSSOS (Kephalopoulos et al., 2012), the European noise prediction standard, for strategic noise mapping in the EU. However, studies that have tested CNOSSOS in Denmark have been limited (Khan et al., 2020). 
Moreover, freely available noise prediction models are also gaining popularity due to their easy access. TRANEX (Gulliver et al., 2015), a parametrised noise prediction method, is one such model which is based on the modified UK standard methodology, the Calculation of Road Traffic Noise (CoRTN) (The UK Department of Transport, 1998), and applied at several locations across the EU (e.g. Tonne et al., 2016). All the above models, besides source characterisation, make use of advanced numerical methods (e.g. wave and continuity equations) to address sound propagation effects and utilise highperformance computers to generate noise maps. Hence, it is important to compare these models scientifically to analyse their suitability, for example, in terms of noise mapping and exposure assessment.

Few studies have compared CNOSSOS with the regional standards ${ }^{1}$, e.g. Bertellino et al., (2016) in Italy, Kokkonen (2018) in Finland, Vergoed and van Leeuwen (2018) in the Netherlands. In addition, Steele (2001) and Garj and Maji (2014) reviewed various traffic noise models based on technical attributes (meteorological effects, etc.). Nevertheless, noise models are continuously improved, and this leaves a need for updating and supplementing the above comparisons. To the authors' knowledge, studies that explicitly compare the source and the propagation modules of CNOSSOS and Nord2000 in the Danish context, have not previously been conducted. Moreover, we have found no studies in the literature on the comparison of TRANEX with existing noise models.

Therefore, the main aim of this paper is to compare CNOSSOS, Nord2000 and TRANEX in terms of their source and propagation characteristics as well as noise estimates and, when possible, explain why these tools provide different noise estimates for some configurations.

\section{CNOSSOS, Nord2000 and TRANEX}

In the following, a brief overview of CNOSSOS (Kephalopoulos et al., 2012), Nord2000 (Kragh et al., 2006; Kragh, 2009a; Kragh, 2011) and TRANEX (Gulliver et al., 2015) is presented. The description,

\footnotetext{
${ }^{1}$ For example, French standard XPS 31-133 (SETRA-CERTU-LCPC, 1997).
} 
where applicable, is organised according to the source and the propagation modules of the different models.

\subsection{Overview of CNOSSOS}

In terms of CNOSSOS' source description, the sound power of a vehicle is treated as a function of the traffic speed $v$ and the frequency $f$ in octave bands (see Supplementary Figure S1, Appendix A), in the range $63 \mathrm{~Hz}-8 \mathrm{kHz}$. It is computed by the following equations (1) and (2) (Kephalopoulos et al., 2012).

$$
\begin{aligned}
& L_{W R}(f, v)=A_{R}(f)+B_{R}(f) \log \left(\frac{v}{v_{r e f}}\right) \\
& L_{W P}(f, v)=A_{P}(f)+B_{P}(f)\left(\frac{v-v_{r e f}}{v_{r e f}}\right)
\end{aligned}
$$

where $L_{W R}$ is the sound power level of rolling noise, $L_{W P}$ is the sound power level of propulsion noise, $v$ is the vehicle speed, $v_{\text {ref }}$ is the reference vehicle speed $(70 \mathrm{~km} / \mathrm{h}), A_{R}$ and $B_{R}$ are the rolling noise coefficients, $A_{P}$ and $B_{P}$ are the propulsion noise coefficients.

The rolling and propulsion noise coefficients are given in Kephalopoulos et al., (2012). Equations 1 and 2 are valid for certain reference conditions. These conditions are (i) constant vehicle speed $\left(v_{\text {ref }}=70\right.$ $\mathrm{km} / \mathrm{h}$ ) (ii) flat and dry road surface consisting of a mixture of Dense Asphalt Concrete (DAC) and Stone Mastic Asphalt (SMA) between two and seven years old (iii) $20^{\circ} \mathrm{C}$ air temperature (iv) no studded tyres. Otherwise, various types of corrections, e.g. road surface type, gradient, acceleration, deceleration are applied to equations 1 and 2 . The road surface correction for rolling noise is given by the following equation (3); other corrections can be found in Kephalopoulos et al., (2012).

$$
\Delta L_{W R, \text { road }, i, m}=\propto_{i, m}+\beta_{m} \log \left(\frac{v}{v_{\text {ref }}}\right)
$$

where $\Delta L_{W R, \text { road }, i, m}$ is the effect of a road surface on rolling noise (for each frequency band $i$ and vehicle category $m$ ) that deviates from the reference road conditions mentioned above, $\propto_{i, m}$ is the 
spectral correction in $\mathrm{dB}$ at reference vehicle speed $\left(v_{r e f}=70 \mathrm{~km} / \mathrm{h}\right), \beta_{m}$ is the speed effect on rolling reduction for each vehicle category $m, v$ is the vehicle speed.

Vehicles are split into four categories, Light-duty Vehicle (LDV), Medium-duty Vehicle (MDV), Highduty Vehicle (HDV), and two-wheelers (motorcycles and mopeds). There is also an open category for future needs. Each vehicle is represented by a point source $(0.5 \mathrm{~m}$ above the road surface) at the lateral centre of the vehicle. NMBP-2008 (Sétra, 2009). The CNOSSOS propagation module, using the principle of ray theory, calculates the attenuation of sound during its propagation from source to receiver for (i) homogenous atmospheric conditions (ii) downward-refraction propagation (favourable) conditions. The former and the latter represent null and positive vertical gradients of effective sound celerity ${ }^{2}$ over the entire area of propagation. the sound level in homogenous and favourable or downwind conditions (unfavourable being up-wind or no wind). Calculations are performed from $63 \mathrm{~Hz}$ to $8 \mathrm{kHz}$ (octave band), and up to $2 \mathrm{~km}$ maximum path distance from the source to the receiver (receiver height $\geq 2 \mathrm{~m}$ ). The long-term sound level $L_{L T}$ is calculated as a sum of levels in favourable conditions $L_{F}$ and in homogenous conditions $L_{H}$ weighted by the probability of occurrence of favourable conditions, given by the following equation (4) (Maijala et al., 2016).

$$
L_{L T}=10 \log \left(p_{f} 10^{p_{f} / 10}+\left(1-p_{f}\right) 10^{L_{H} / 10}\right)
$$

\footnotetext{
${ }^{2}$ Sound celerity is also known as the speed of sound.
} 
where $p_{f}$ is the probability of occurrence of downward-refraction conditions in the long term. The $p_{f}$ values are given in percentages for the day (07:00 - 19:00), evening (19:00 - 22:00) and night (22:00 $-07: 00)$ periods.

The CNOSSOS propagation module does not take into account propagation scenarios over water bodies (lake, river, etc.). The calculation procedure is briefly described in the next paragraphs.

For each point source, the directional sound power is determined, and for each direction from source to receiver, the probability of favourable conditions is estimated. Depending on the terrain, the propagation path (i.e. direct, reflected or diffracted) is determined. On each path, attenuations in the favourable and the homogenous conditions are calculated, which include several effects, e.g. ground effect, geometrical divergence ${ }^{3}$, reflections (building façades), and diffraction corrections.

A simplified concept of "mean ground plane" between source and receiver is applied in ground effect attenuations. In this empirical approach, the actual ground is replaced with an imaginary plane representing the mean profile of the ground. The sound level for each path is calculated, and subsequently, accumulated to compute the total sound level at the receiver point. Further details regarding CNOSSOS method are provided in Kephalopoulos et al., $(2012,2014)$.

\subsection{Overview of Nord2000}

Nord2000 is a point-to-point method. In terms of its source module, the sound power level is calculated for rolling and propulsion noise using the same equations 1 and 2 , but in $1 / 3$ octave bands (see Supplementary Figure S2, Appendix A), and in the range $25 \mathrm{~Hz}-10 \mathrm{kHz}$. The default Nord2000 coefficients $\left(A_{R}, B_{R}\right.$ and $\left.A_{P}, B_{P}\right)$ based on $1 / 3$ octave band emission database (Andersen, 2003) are provided in Jonasson (2006). The Nord2000 source module broadly follows the same reference conditions (Kragh et al., 2006) as CNOSSOS (see section 2.1). For the cases that do not follow the reference conditions, Nord2000 uses several corrections in terms of the road surface, gradient,

\footnotetext{
${ }^{3}$ The reduction in the sound level due to propagation distance (Kephalopoulos et al., 2012).
} 
acceleration/deceleration etc. In addition, corrections in rolling noise for temperatures other than $20^{\circ} \mathrm{C}$ and wet road surface (LDV only) are applied.

In the Nord2000 model, vehicles are generally categorised the same way as CNOSSOS. That is LDV, MDV, HDV and two-wheelers including motorcycles/mopeds. These categories are further divided into sub-categories based on the number of axles and the length of the vehicle. However, only three main categories (LDV, MDV and HDV) are used in noise prediction (Kragh et al., 2006; Kragh 2011). An LDV is represented by two point sources, at $0.01 \mathrm{~m}$ and $0.3 \mathrm{~m}$ respectively above the ground, whereas, MDV and HDV are designated at a source height of $0.01 \mathrm{~m}, 0.75 \mathrm{~m}$ and possibly $3.5 \mathrm{~m}$. The sources are placed laterally at the nearest wheels relative to the receiver point.

The sound propagation module of Nord2000 is based on geometrical ray theory. It provides algorithms to calculate sound attenuation ( $1 / 3$ octave band, $25 \mathrm{~Hz}-10 \mathrm{kHz})$ along the propagation path by considering, e.g. terrain shape, ground type (Kragh, 2011). The terrain cross-section is broken down into $10-15$ straight-line segments to accumulate contributions from all segments to resulting ground and screening effects. Each segment is assumed to be perfectly flat; otherwise, the value of the ground roughness ${ }^{4}$ is specified. The sound pressure level $L_{R}$ at the receiver for each frequency band is given by equation (5) (Plovsing, 2006a).

$$
L_{R}=L_{W}+\Delta L_{d}+\Delta L_{a}+\Delta L_{r}+\Delta L_{s}+\Delta L_{t}
$$

where $L_{W}$ is the sound power level within the considered frequency band, $\Delta L_{d}$ is the propagation effect of spherical divergence of the sound energy, $\Delta L_{a}$ is the propagation effect of air absorption, $\Delta L_{r}$ is the propagation effect of obstacle dimensions and surface properties when calculating a contribution from sound reflected by an obstacle, $\Delta L_{s}$ is the propagation effect of scattering zones, $\Delta L_{t}$ is the propagation effect of the terrain (ground and barriers).

\footnotetext{
${ }^{4}$ Ground roughness (also known as ground unevenness) is significant in terms of acoustic impedance. It the RMS value of the ground height fluctuations within the segment (EC, 2007).
} 
In terms of ground effect, Nord2000 makes use of the Fresnel zones ${ }^{5}$ (see Figure 1). It is the concept proposed by Hothersall and Harriot (1995) to predict sound propagation (approximate solution) over flat terrain with varying ground types. The Fresnel zone approach assumes that the sound at the receiver is determined by surface conditions in that region around the reflecting point. When the sound is reflected from a plane surface, the intersection between the surface and Fresnel-ellipsoid creates the elliptically shaped Fresnel zone (Garg and Maji, 2014). The ground effect is calculated for each ground type found inside the Fresnel zone. Then, the overall ground effect is given as the weighted-average by considering the fraction of the Fresnel zone covered by each ground type (Kragh, 2011; The Danish Road Directorate, Report 195/2011). The Fresnel ellipsoid is defined by the locus of the points P given by the following equation (6) (Plovsing, 2006a).

where $S$ is the source point, $R$ is the receiver point, $F_{\lambda}$ is a fraction of the wavelength $\lambda$. The foci of the ellipsoid are placed at $S$ and $R$.

The Nord2000, based on flow resistivity, utilises eight ground types for ground effect corrections. Details regarding each ground type can be found in Kragh (2011). In short, these types vary from "very soft" (moss-like) to "very hard" (Dense Asphalt Concrete) (DAC). Moreover, in terms of meteorology, there are 25 weather classes. Each class is (i) classified by a 'profile' of the sound speed as a function of height above the ground (Plovsing, 2006a) (ii) linked to the certain curvature of the sound waves. The 'effective' sound speed is approximated by the following equation (7).

$$
C=A \ln \left(1+\frac{z}{z_{0}}\right)+B z+C(0)
$$

\footnotetext{
${ }^{5}$ A Fresnel zone is one the series of confocal elongated ellipsoidal regions of space between and around source and receiver (Large and Farmer, 2009).
} 
where $z$ is the height above the ground surface, $z_{0}$ is a constant interpreted as the roughness length, $A$ is the coefficient of the logarithmic term $(\mathrm{m} / \mathrm{s}), B$ is the coefficient of the linear term $(1 / \mathrm{s}), C(0)$ is the sound speed at height $z=0 \mathrm{~m}(\mathrm{~m} / \mathrm{s})$.

For more aspects of the Nord2000 sound propagation module, interested readers are referred to Kragh et al., (2006).

\subsection{Overview of TRANEX}

TRANEX (Gulliver et al., 2015) is a modified version of the Calculation of Road Traffic Noise (CoRTN) method (The UK Department of Transport, 1998). As such, TRANEX does not explicitly distinguish between its source and propagation modules. However, source emission levels and various corrections (e.g. façade reflections) have otherwise been incorporated into the model algorithms. The following paragraphs summarise the main aspects of CORTN and TRANEX methodologies.

In the CoRTN, noise estimates are given as $L_{A 10,1 h r}$, which is A-weighted hourly $L_{10}$ (the noise level exceeded for $10 \%$ of the time, $d B A$ ), and $L_{A 10,18 h}$, the noise level for the period $06: 00$ until 0:00. The $\mathrm{L}_{\mathrm{A} 10,1 \mathrm{hr}}$ is calculated according to the following equation (8):

$$
L_{A 10,1 h r}=L_{0}+\Delta_{f}+\Delta_{g}+\Delta_{p}+\Delta_{d}+\Delta_{s}+\Delta_{c}+\Delta_{a}+\Delta_{r}
$$

where $L_{0}$ is the basic noise level estimated at a distance of $3.5 \mathrm{~m}$ from the kerbside and $0.5 \mathrm{~m}$ above the ground, $\Delta_{f}$ is the correction in terms of traffic speed and percentage of HDV, $\Delta_{g}$ is the road gradient correction, $\Delta_{p}$ is the road surface correction (DAC, etc.), $\Delta_{d}$ is the distance (slant distance between source and receiver) correction, $\Delta_{S}$ is the shielding correction (i.e. barriers between source and receiver), $\Delta_{c}$ is the ground cover attenuation, $\Delta_{a}$ is the correction for the angle of view of the road, $\Delta_{r}$ is the building reflections correction. All noise levels in equation 8 and the following equations are in $\mathrm{dBA}$ units. 
In terms of vehicles, two categories, i.e. LDV and HDV, are used. Each vehicle is represented by a point

where $q$ is the hourly traffic flow in the vehicle per hour.

In terms of traffic speed and HDV, for example, the CoRTN applies the following corrections (see supplementary material, Appendix B, for other correction equations, $\Delta_{g}, \Delta_{p}$, etc.):

$$
\Delta_{f}=33 \log \left(v+40+\frac{500}{v}\right)+10 \log \left(1+\frac{5 p}{v}\right)-68.8
$$

where $v$ is the mean hourly traffic speed $(\mathrm{km} / \mathrm{h}), p$ is the percentage of the HDV.

After several corrections, the noise level from all sources $\left(L_{1}, L_{2}, \ldots L_{n}\right)$ is combined using the following equation:

$$
L=10 \log \left[\sum_{1}^{n} 10^{L_{n} / 10}\right]
$$

where $L$ being the estimated noise level from $n$ sources.

Further information regarding the CoRTN method can be found in the official documentation (The UK Department of Transport, 1998) as well as other relevant articles (e.g. Pamanikabud and Tansatcha, 2003; Garj and Maji, 2014), and will not be repeated here. The next paragraph presents the main aspects of TRANEX.

The TRANEX model calculates the noise level using above equations $8-11$, and subsequently, makes use of the following empirical relationship (Abbot and Nelson, 2002) to calculate $L_{A e q, 1 h r}$ (the Aweighted hourly equivalent noise level):

$$
L_{A e q, 1 h r}=0.94 L_{10,1 h r}+0.77
$$

where $L_{10,1 h r}$ is calculated using equation (8). source ( $0.5 \mathrm{~m}$ above the road surface). The TRANEX method is valid for distances up to $1000 \mathrm{~m}$ (user 
adjustable), that is, the shortest path distance between each source and receptor. It is created using straight-line geometry to take into account various corrections (e.g. ground cover, screening) along the propagation path. See Gulliver et al., (2015) for more information regarding TRANEX.

\section{Comparison of models}

This section describes the materials and methods used to compare CNOSSOS, Nord2000 and TRANEX. The comparison has been divided into two parts (i) source and propagation modules, (ii) test cases simulations.

\subsection{Source and propagation modules}

257

The source and propagation modules (selected characteristics) of CNOSSOS, Nord2000 and TRANEX have been compared. The main aim was to highlight similarities and differences among models in terms of their source and propagation characteristics. In addition, the general input parameters are also compared. The results of the comparisons are given in sections 4.1 and 4.2.

\subsection{Test cases and software implementation}

To compare simulated noise $\left(L_{A e q}\right)$ of CNOSSOS, Nord2000 and TRANEX, more than one hundred test cases ( $N=111$, similar geographical characteristics) have been developed, including a variety of land cover profiles, source, and propagation configurations (LDV, traffic speed, $S-R$ distance, building height, etc.). The test cases represented the "real" geographical settings and were developed using the 'type cases' given in the Nord2000 Road (N2kR) software, which is described later in this section.

There are two main categories. The first test cases (case 1 - 57) are based on "simple" scenarios, such as straight, dense asphalted roads with no building reflections or obstacles, whereas, the later ones (case 58 - 111) include building reflections. Each test case is further divided into sub-cases based on varying $S-R$ distance $(8-48 \mathrm{~m})$, traffic speed $(40-120 \mathrm{~km} / \mathrm{h}$ ), LDV and HDV (500 - $50000 \mathrm{veh} /$ day) 
or building height $(5-25 \mathrm{~m})$. See Supplementary Tables S1 and S2 for all test cases' configurations.

We used CNOSSOS (Kephalopoulos et al., 2012), implemented by Morley et al., (2015) (type "F", the highest resolution in terms of geographical inputs), developed in relation to the European noise exposure cohort study, the BioSHaRE (http://www.bioshare.eu/) (e.g. Cai et al., 2017). The model algorithms (Kephalopoulos et al., 2012) are implemented in open-source PostgreSQL software (hereafter, Postgres) (PostgreSQL Global Development Group, 2020), where model calculations are performed via its spatial extension called PostGIS (PostGIS Development Team, 2020). The detailed information regarding the model operation, testing and evaluation is provided in Morley et al., (2015), and will not be described in detail here. In short, CNOSSOS (Morley et al., 2015) makes use of various corrections (via GIS operations) to estimate sound power levels at the source and the receiver sides, which are logarithmically summed to predict noise (e.g. hourly $\left.L_{A e q, 0-23 h}\right)$. The hourly noise levels are subsequently used to compute 24 hourly $L_{A e q}$ using the following equation (Brink et al., 2018):

$$
L_{A e q}=10 \log \left(\frac{1}{24} \sum_{h=0}^{23} 10^{0.1 L_{A e q, h}}\right)
$$

where $h$ is the index for the hour of the day (e.g. $h=19$ is hour 19:00 to 19:59:59).

Few studies have tested CNOSSOS for its implementation in the Nordic countries, e.g. Kokkonen et al., (2018) in Finland, and Larsson, (2016) in Sweden. They suggest the use of Nordic sound power coefficients (Jonasson, 2006) instead of the default coefficients in the model algorithms. The default coefficients, therefore, were replaced by the Nordic ones to reflect upon "standard" Nordic road surface conditions as described in Kragh, (2011). (http://www.soundplan.dk/). The Norwegian research organisation SINTEF (SINTEF ICT, 2020) developed a software Nord2000 Road - Type Cases 1.1 ("N2kR-TC version 1.1") that makes use of the 

based on weather conditions, traffic speed and composition, building areas, etc. (Danish Road Directorate, 2011). The user interface of N2kR-TC is illustrated in Supplementary Figures S3 and S4 (Appendix C). In this study, we used this freely available tool from SINTEF (SINTEF ICT, 2020) to obtain pre-simulated $L_{A e q}$ levels for all test cases using Nord2000 (2006 version).

The TRANEX model algorithms, described in section 2.3, were implemented in Postgres database via R software version 4.0.0. ( $R$ Core Team, 2020) to reflect various test case configurations (see supplementary Tables S1 and S2, Appendix C). The A-weighted hourly noise levels were calculated by equation 7 (section 2.3), and subsequently used to compute $L_{\text {Aeq }}$ levels using equation 8 . The traffic speed and $\operatorname{HDV}\left(\Delta_{f}\right)$, road surface $\left(\Delta_{p}\right)$, and distance $\left(\Delta_{d}\right)$ corrections were applied to the test cases 1 - 57 based on "no buildings" scenario. For the cases involving buildings (case $58-111$ ), building reflections $\left(\Delta_{r}\right)$ and angle of view $\left(\Delta_{a}\right)$ (where applicable) corrections were additionally applied. All corrections were implemented according to the guidelines provided in the official CoRTN manual (The UK Department of Transport, 1998, pp. 63 - 64).

The GIS inputs (e.g. receiver points, building polygons) for CNOSSOS and TRANEX were prepared in the QGIS software (QGIS Development Team, 2020); see Supplementary Figure S5 (Appendix C). The input files were imported into a Postgres database, where an automatic script was used to update each test case's configuration (traffic values, $\mathrm{S}-\mathrm{R}$ distance, etc.). Subsequently, CNOSSOS and TRANEX model algorithms were used to simulate noise levels. All simulations were performed under neutral weather conditions to allow comparative assessments. For Nord2000, the weather case was set to "uniform atmosphere", whereas, for CNOSSOS, the meteorological condition was set to $0 \%$, i.e., "favourable propagation". As such, for TRANEX, there are no adjustable weather conditions.

The simulated $L_{A e q}$ levels of CNOSSOS, Nord2000 and TRANEX are compared. The absolute difference,

$318|\Delta|$ in dBA, among the predicted noise levels, and Pearson's correlation coefficients $(R)$ are computed. 
320 (Med), Maximum (Max), Mean Bias (MB), Mean Absolute Error (MAE), Root-mean squared error

321 (RMSE), as well as $95 \%$ Confidence Interval $(\mathrm{Cl})$, have been calculated. The definitions of the aforementioned statistical measures are provided in Supplementary material (Appendix D). All statistical analyses were performed in $\mathrm{R}$ software version 4.0.2. In addition, the percentage of CNOSSOS and TRANEX $L_{A e q}$ predictions in the intervals $0-1 \mathrm{dBA}, 1-3 \mathrm{dBA}$ and $3-5 \mathrm{dBA}$ of the corresponding Nord2000 predictions are calculated.

It was not possible to perform field measurements due to cost and time constraints. In addition, measured noise data from monitoring stations as well as previous campaigns (e.g. Danish Road Directorate, Technical note \# 61, 2007) needed to be thoroughly checked and verified, i.e. synergy between modelled and measured noise, measurement location equal to our test cases simulations scenarios (free-field, on a wall, etc.), which required longer time significantly. Therefore, simulated noise is not compared with the measured ones. Moreover, due to the nature of the present study ("pure" model inter-comparisons), the use of measurements was out of the scope here and will be part of future research.

\section{Results}

This section presents the results of the model intercomparisons, which are subsequently discussed in detail in section 5 . In sub-section 4.3, a few test cases have been selected, and later discussed (section 5) to further illustrate similarities and differences between CNOSSOS, Nord2000 and TRANEX.

\subsection{Source modules}

Table 1 shows comparison results of the source characteristics of CNOSSOS, Nord2000 and TRANEX. The TRANEX, being an empirical method, differs significantly from the others. Although, the source modules of CNOSSOS and Nord2000 are somewhat similar to each other (e.g. reference speed and temperature); they work in a slightly different way. The frequency spectrum of CNOSSOS is given in 
broader frequency bandwidth (Scholl et al., 2012), it suffers from a lack of information (e.g. SPL, resonance). The Nord2000 utilises frequency spectrum in the $1 / 3$ octave bands, which provides information much more clearly about the noise, i.e. rolling and propulsion sound power emanating from the source (Berger, 2003).

The estimation of rolling and propulsion noise is handled the same way by CNOSSOS and Nord2000 (Table 1). Both models use equation 1 and 2 for the same reference speed $\left(v_{r e f}\right), 70 \mathrm{~km} / \mathrm{h}$. The sound power coefficients $\left(A_{R}, B_{R}\right.$ and $\left.A_{P}, B_{P}\right)$ of CNOSSOS and Nord2000, however, are based on the different noise emissions databases (Table 1). The existing Nord2000 coefficients are based on measurements performed mainly in Denmark (Kragh, 2011), whereas, the CNOSSOS default coefficients are based on measurements performed in the EU project IMAGINE (Van Blokland and Peeters, 2007). Peters and Van Blokland (2018) recently reported errors in the CNOSSOS' default coefficients. The authors further stated that CNOSSOS, for most of the frequency range, will underestimate or overestimate noise levels up to $3 \mathrm{~dB}$ using default EU coefficients.

TRANEX does not distinguish between rolling and propulsion noise (Table 1). The model, unlike CNOSSOS and Nord2000, uses empirical emission curves to estimate basic noise level at a reference distance of $10 \mathrm{~m}$ from the nearside roadway.

In general, both CNOSSOS and Nord2000 handle the effects of road gradient and surface the same way. That is several correction terms, as a function of slope and vehicle speed and category, are applied to the computed noise levels. TRANEX, however, handles the gradient effect differently by an empirical relationship (see Table 1).

\subsection{Propagation modules} TRANEX. Here, the model differences can clearly be seen (Table 2). 
One of the limitations of TRANEX is that it does not utilise meteorological data (e.g. air temperature, wind speed) to take into account sound attenuation under the different weather conditions (Table 2). The corresponding effect in CNOSSOS is taken into account by carrying out the calculation of sound levels in favourable and homogeneous conditions (equation 4, section 2.1), which depends on the probability of occurrence of the former (Maijala et al., 2016). In contrast, the Nord2000 model uses 25 weather classes characterised by several weather coefficients (Kragh, 2011).

The sound attenuation due to geometrical divergence is given as a function of $\mathrm{S}-\mathrm{R}$ distance in both CNOSSOS and Nord2000 and calculated by empirical relationships (see Table 2). TRANEX handles the geometrical divergence effect in a slightly different way. It calculates shortest 'slant distance' (see Supplementary Figure S6, Appendix E) between source and receiver, which is based on the shortest $\mathrm{S}$ - $\mathrm{R}$ distance and the difference in height above the ground between source and receiver.

The methods used to estimate ground effect attenuations are also different (Table 2). Here, CNOSSOS uses the concept of "mean" ground plane (see section 2.1). Whereas, TRANEX uses the "mean" propagation height (the difference between the source and receiver heights) as well as empirically derived percentages of the absorbent ground to achieve the same. Nord2000, in contrast, uses a more sophisticated approach. The model utilises coherent superposition of the direct and the reflected rays based on their different lengths as well as the ground impedance (Probst, 2010a, b). In this process, the techniques of Fresnel zones and Chien and Soroka approximations (Chien and Soroka, 1980) are applied (Table 2).

It is also clear from Table 2 that the techniques used to calculate diffraction effects are substantially different. TRANEX applies the empirical approach based on the path difference; CNOSSOS and Nord2000 use several algorithms to calculate sound attenuation due to diffraction. Nord2000, in particular, makes use of several advanced methods (e.g. the Jonasson image method: Jonasson, 1980) 

F), where Nord2000 uses a comprehensive set of inputs (e.g. relative humidity, surface roughness) to estimate noise levels as compared to CNOSSOS and TRANEX.

\subsection{Test cases simulations}

395

396

This section presents the results of test cases simulations for several configurations using CNOSSOS, Nord2000 and TRANEX.

Figure 2 and Table 3 show the simulation results, predicted $L_{\text {Aeq }}(d B A)$, and their comparisons for the selected test cases based on varying $S-R$ distance and LDV. The results are based on a simple scenario of sound propagation over the flat and hard ground with no building reflections (similar geographical setting). Complete simulation results and their summary statistics are provided in Appendix $\mathrm{G}-\mathrm{H}$ and Supplementary Table S5 (Appendix I). The agreement and disagreement among predicted $\mathrm{L}_{\text {Aeq }}$ of CNOSSOS, Nord2000, and TRANEX can be seen (Figure 2). The agreement, in some cases, seems to be poor (Case 51, Figure 2a); in others, the models agree well (Case 17, Figure 2b). The absolute difference among predicted $L_{\text {Aeq }}$ was in the range: $|\Delta|=0.1-4.3 \mathrm{dBA}$ (CNOSSOS and Nord2000), and $|\Delta|=0-3.7 \mathrm{dBA}$ (TRANEX and Nord2000) (see Table 3).

Figure 3 shows the comparison of predicted $L_{\text {Aeq }}(d B A)$ at varying traffic speed for the selected test cases, whereas, Figure 4 shows the same at varying $S-R$ distance and LDV. Here, results reflect upon a scenario that is based on sound propagation over the flat and hard ground with building reflections (similar geographical setting) (see Appendix $\mathrm{G}-\mathrm{H}$ for complete results). Both CNOSSOS and TRANEX showed significant differences with Nord2000 $L_{\text {Aeq }}$ estimates in most of the speed range (Figure 3 ), in particular, at higher speeds (e.g. $100-120 \mathrm{~km} / \mathrm{h}$, Case 110). Here, CNOSSOS $\mathrm{L}_{\text {Aeq }}$ estimates deviated from Nord2000 ones up to $7 \mathrm{dBA}$, while TRANEX up to $5.2 \mathrm{dBA}$ (Table 3).

Similar differences can also be seen in Figure 4a, where CNOSSOS/Nord2000 and TRANEX/Nord2000 showed significantly different dispersions in the estimated $L_{\text {Aeq }}$ for cases based on varying $S-R$ 
distance (difference: $0.6-5 \mathrm{dBA}$ for CNOSSOS; $0.3-7 \mathrm{dBA}$ for TRANEX). The test cases that include buildings with varying LDV (Figure 4b) showed similar results to the ones without buildings (Figure $2 b$ ). Again, a good match (e.g. Case 91, Figure 4b), as well as a mismatch (e.g. Case 104, Figure 4b) between the models, can be observed. Here, the difference between CNOSSOS and Nord2000 $L_{\text {Aeq }}$ estimates varied in the range $0-3.1 \mathrm{dBA}$, whereas, between TRANEX and Nord2000, the difference was $0.1-$ 4.6 dBA (see Table 3).

In summary, the overall difference (all results, Appendix $\mathrm{G}-\mathrm{H}$ ) in the predicted $\mathrm{L}_{\text {Aeq }}$ levels varied in the range $0-7.3 \mathrm{dBA}$ (CNOSSOS vs Nord2000) and 0 $-7.2 \mathrm{dBA}$ (TRANEX vs Nord2000). Both CNOSSOS and TRANEX have non-zero Mean Absolute Error (MAE) for the different cases (MAE: 0.8 - 3.9 dBA for CNOSSOS; $1.8-2.6$ dBA for TRANEX) (see Table S5). Moreover, the overall mean bias (MB) between the models was statistically significant: CNOSSOS $=-1.5 \mathrm{dBA}(95 \% \mathrm{Cl}=[-3.1,4.9])$, TRANEX: -1.2 $\mathrm{dBA}(95 \% \mathrm{Cl}=[-2.8,5.0])$. Furthermore, the Pearson's correlation (all results, see Figure 5 ) was $\mathrm{R}=$ 0.96 (CNOSSOS vs Nord2000), and R = 0.97 (TRANEX vs Nord2000).

Figure 6 shows the comparison of $L_{\text {Aeq }}$ predictions from CNOSSOS and TRANEX in the intervals $0-1$ $\mathrm{dBA}, 1-3 \mathrm{dBA}$ and $3-5 \mathrm{dBA}$ of the corresponding Nord2000 values. The comparison is given for the different categories (e.g. LDV, speed). For the cases without buildings (Figure 6a), CNOSSOS, overall, performed better than TRANEX, for example, by producing more predictions in the interval $0-1 \mathrm{dBA}$ (e.g. 79\%, LDV) of the corresponding Nord2000 values. For the cases that included buildings (Figure $6 b)$, it can be seen that CNOSSOS, overall, performed better than TRANEX except for the varying speed. Here, the former performed worse than the later with $3 \% L_{\text {Aeq }}$ predictions in the $0-1 d B A$ interval (Nord2000 data), $20.7 \%$ in the $1-3 \mathrm{dBA}$ interval and $41.5 \%$ in the $3-5 \mathrm{dBA}$ interval.

\section{Discussions}

The simulation results presented above should be carefully interpreted. Besides the fact that both 
analyses presented here are based on the "2006 version" of the Nord2000 method. Therefore, Nord2000 $L_{\text {Aeq }}$ estimates do not reflect upon several minor revisions and adjustments (see Plovsing, 2014 for more details) that has been done in the model algorithms since 2006. Consequently, the simulated noise comparisons of CNOSSOS, Nord2000 and TRANEX in this study could be uncertain to an unknown extent.

As noticed above (Figures $2-4$ ), there were several differences in the estimated $\mathrm{L}_{\text {Aeq }}$ of CNOSSOS, Nord2000 and TRANEX. This is due to several inherent differences in their source and propagation characteristics as well as inputs (see section 2). For instance, the computation of the probability of downward refraction conditions in CNOSSOS, which still requires extensive evaluations (Garg and Maji, 2014), compared to Nord2000's comprehensive set of weather classes. Moreover, TRANEX does not use meteorology in noise estimation. All this explains why above models generally provide different noise estimates for specific configurations.

In addition, CNOSSOS performed worse for the cases based on varying speed (Figures 3 and 6). This can potentially be linked to the inconsistencies in CNOSSOS' default sound power coefficients. The same issue has also been highlighted by Peters and Van Blokland (2018), as stated in section 4.1. Moreover, the $L_{A e q}$ estimates of CNOSSOS and TRANEX were within five $d B A$ of the corresponding Nord2000 values. These deviations varied across the full range of Nord2000 estimates and were statistically significant (see Figure 6 and Table S5). It is, therefore, reasonable to conclude that both CNOSSOS and TRANEX, with a few exceptions, can reproduce $L_{\text {Aeq }}$ levels of Nord2000 within $3-5 \mathrm{dBA}$ for a variety of cases.

Several researchers have evaluated CNOSSOS for its implementation in the EU member states and reported several discrepancies in the model algorithms. Vergoed and van Leeuwen (2018) validated CNOSSOS in the Netherlands and reported errors in its propagation module related to multiple diffractions under favourable condition. Probst (2019) also reported the same errors but highlighted 
464 (2019) found numerous discrepancies in the CNOSSOS algorithms, which are related to ground attenuation, modified heights with ground attenuation, mean ground plane, and the same favourable conditions' errors reported by van Leeuwen and Probst assessments. All the above uncertainties may also explain the difference in CNOSSOS/Nord2000 $\mathrm{L}_{\text {Aeq }}$ estimates in this study (see Table 3 and Appendix $G-1)$.

It is clear that due to fundamental errors in the propagation module, more work is required to improve CNOSSOS. An EU working group, led by the Dutch National Institute for Public Health and Environment, RIVM, has recently summarised all issues and proposed amendments to the CNOSSOS method (RIVM Report \# 2019-0023, 2019). It will be interesting to see the implications of these amendments.

Examples of differences between CNOSSOS and Nord2000 noise estimates can also be seen in the literature. Larson (2016) compared sound power levels computed by CNOSSOS and Nord2000 at varying speed in Sweden and reported systematic CNOSSOS' under-predictions in the range $0.1-4$ dB. Another study, Kokkonen et al. (2016) tested CNOSSOS for its implementation in Finland. They compared noise estimates of CNOSSOS and Nord2000 for LDV, MDV and HDV at varying speed (40 $120 \mathrm{~km} / \mathrm{h}$ ), and reported model differences in the range $0.7-4.6 \mathrm{~dB}$.

In terms of TRANEX vs Nord2000, none of the studies were found in the literature that compared their noise estimates. So it was not possible to quantify possible uncertainties in $L_{\text {Aeq }}$ estimates of TRANEX and compare our findings.

Moreover, as stated in sub-section 3.2, model results are not compared with the measurements mainly due to cost and time constraints. Also, the use of measurements was out of the scope of the paper due to its nature (models intercomparisons). The lack of noise measurements and models evaluation, however, highlight one of the significant limitations of this study which needs to be addressed in the future work. 
In this paper, CNOSSOS, Nord2000 and TRANEX are compared in terms of their source and propagation features. In addition, the simulated $\mathrm{L}_{\text {Aeq }}$ levels of CNOSSOS, Nord2000 ("2006" version) and TRANEX are also compared. The comparison of $\mathrm{L}_{\text {Aeq }}$ levels is performed for more than one hundred test cases involving a variety of source and receiver configurations (e.g. traffic speed, source to receiver distance).

There are many inherent differences among CNOSSOS, Nord2000 and TRANEX. In particular, all these models handle diffraction and refraction quite differently. It is also the case for sound attenuation due to meteorological conditions. In simple cases without building reflections, both CNOSSOS and TRANEX showed significant deviation from Nord2000 Leq $_{\text {Aeq }}$ estimates (CNOSSOS: $0.1-6 \mathrm{dBA}$, TRANEX: $0-5$ dBA). The agreement among models also deteriorates for the cases with buildings (i.e. noise screens). In summary, CNOSSOS and TRANEX reproduced $L_{\text {Aeq }}$ levels of Nord2000 within $3-5 \mathrm{dBA}$ for the majority of the cases (CNOSSOS: 87\%; TRANEX: 94\%).

The differences between CNOSSOS and Nord2000 $\mathrm{L}_{\text {Aeq }}$ estimates are due to the discrepancies in the CNOSSOS algorithms, e.g. ground attenuation, mean ground plane. More research is required to improve CNOSSOS (sound propagation module) as well as its further testing and evaluation, especially in the EU countries. In this connection, amendments for CNOSSOS proposed by an EU working group hold significant potential. Overall, both CNOSSOS and TRANEX produced similar results, with TRANEX reproducing Nord2000 $\mathrm{L}_{\text {Aeq }}$ values slightly better than the CNOSSOS.

\section{Funding} (Grant \# NNF170C0027864).

\section{Acknowledgements}


The authors gratefully acknowledge the help provided by Frank Pedersen, the Danish Environmental

Protection Agency (EPA). Statements made in this paper are solely the responsibility of the authors.

\section{References}

Abbott, P. G., \& Nelson, P. M. (2002). Converting the UK traffic noise index LA10, 18h to EU noise indices for noise mapping. UK: Transport Research Laboratory.

Andersen, B. (2003). Noise emission from vehicles in ordinary traffic (in Danish) - DTU Transport Rapport 2, ISBN 87-7327-086-5.

Bendtsen, H. (1999). The Nordic prediction method for road traffic noise. Science of the Total Environment, 235(1-3), 331-338.

Berger, E. H. (Ed.). (2003). The noise manual. Aiha.

Bertellino, F., Gerola, F., Clementel, M., Scaramuzza, P., \& Nardelli, M. (2016). Noise Mapping of Agglomerations: a comparison of interim standards vs. new CNOSSOS method in a real case study. In INTER-NOISE and NOISE-CON Congress and Conference Proceedings (Vol. 253, No. 5, pp. 3639-3649). Institute of Noise Control Engineering.

Brink, M., Schäffer, B., Pieren, R., \& Wunderli, J. M. (2018). Conversion between noise exposure indicators $L_{\text {eq2 } 2 h, ~} L_{\text {Day }}, L_{\text {Evening, }} L_{\text {Night }}, L_{d n}$ and $L_{\text {den }}$ : Principles and practical guidance. International journal of hygiene and environmental health, 221(1), 54-63.

Cai, Y., Zijlema, W. L., Doiron, D., Blangiardo, M., Burton, P. R., Fortier, I., ... \& Mbatchou, S. (2017). Ambient air pollution, traffic noise and adult asthma prevalence: a BioSHaRE approach. European Respiratory Journal, 49(1), 1502127.

Chien, C., \& Soroka, W. (1980). A note on the calculation of sound propagation along an impedance surface. Journal of Sound Vibration, 69, 340-343.

Danish Environmental Protection Agency (EPA) (2020). Nord2000: Nordic noise prediction method. Available online: https://eng.mst.dk/air-noise-waste/noise/traffic-noise/nord2000-nordicnoise-prediction-method/. 
Danish Road Directorate (2007). Noise classification - asphalt pavement. Technical note \# 61. Available online: https://www.vejdirektoratet.dk/api/drupal/sites/default/files/publications/noise classificatio n.pdf.

Danish Road Directorate (2011). Traffic noise prediction with Nord2000: An update - Report 1952011. Available online: http://www.vejdirektoratet.dk/DA/viden og data/publikationer/Lists/Publikationer/Attachm ents/737/Endelig\%20rapport\%20195.pdf.

De Lisle, S. (2016). Comparison of road traffic noise prediction models: CoRTN, TNM, NMPB, ASJ RTN. Acoustics Australia, 44(3), 409-413.

European Commission (EC) Working Group Assessment of Exposure to Noise (WG-AEN) (2007). Good Practice Guide for Strategic Noise Mapping and the Production of Associated Data on Noise Exposure. Available online: https://www.Ifu.bayern.de/laerm/eg umgebungslaermrichtlinie/doc/good practice guide 2 007.pdf.

European Commission (EC) (2015). Revisions (Annex II) of the Environmental Noise Directive. Available online: https://eur-lex.europa.eu/legalcontent/EN/TXT/PDF/?uri=CELEX:32015L0996\&from=EN.

European Environment Agency (EEA) (2018). Environmental noise. Available online: https://www.eea.europa.eu/airs/2018/environment-and-health/environmental-noise. European Environment Agency (EEA) (2020). Environmental noise in Europe. Available online: https://www.eea.europa.eu/publications/environmental-noise-in-europe.

Garg, N., \& Maji, S. (2014). A critical review of principal traffic noise models: Strategies and implications. Environmental Impact Assessment Review, 46, 68-81. 
Gulliver, J., Morley, D., Vienneau, D., Fabbri, F., Bell, M., Goodman, P., ... \& Fecht, D. (2015). Development of an open-source road traffic noise model for exposure assessment. Environmental Modelling \& Software, 74, 183-193.

Hadden Jr, W. J., \& Pierce, A. D. (1981). Sound diffraction around screens and wedges for arbitrary point source locations. The Journal of the Acoustical Society of America, 69(5), 1266-1276.

Hothersall, D. C., \& Harriott, J. N. B. (1995). Approximate models for sound propagation above multiimpedance plane boundaries. The Journal of the Acoustical Society of America, 97(2), 918-926.

Jonasson, H. G. (1972). Sound reduction by barriers on the ground. Journal of sound and vibration, 22(1), 113-126.

Jonasson, H. G. (2006). Acoustic Source Modelling of Nordic Road Vehicles. Available online: http://www.vejdirektoratet.dk/DA/vejsektor/forskning-ogudvikling/Miljovenlige\%20veje/Stoj/NORD2000/Documents/PDF\%20til\%20st\%C3\%B8jtema/1 55950.pdf.

Jonasson, H., \& Nielsen, H. (1996). Road traffic noise-Nordic prediction method. Nordic Council of Ministers, Tema Nord, Copenhagen, Denmark, 1996525.

Kephalopoulos, S., Paviotti, M., \& Ledee, F. A. (2012). Common noise assessment methods in Europe (CNOSSOS-EU) (pp. 180 p): Publications Office of the European Union. Available online: https://ec.europa.eu/irc/en/publication/reference-reports/common-noise-assessmentmethods-europe-cnossos-eu.

Kephalopoulos, S., Paviotti, M., Anfosso-Lédée, F., Van Maercke, D., Shilton, S., \& Jones, N. (2014). Advances in the development of common noise assessment methods in Europe: The CNOSSOS-EU framework for strategic environmental noise mapping. Science of the Total Environment, 482, 400-410.

Khan, J., Kakosimos, K., Jensen, S. S., Hertel, O., Sørensen, M., Gulliver, J., \& Ketzel, M. (2020). The spatial relationship between traffic-related air pollution and noise in two Danish cities: Implications for health-related studies. Science of The Total Environment, 138577. 
Khomenko, S., Nieuwenhuijsen, M., Ambros, A., Wegener, S., \& Mueller, N. (2020). Is a liveable city a healthy city? Health impacts of urban and transport planning in Vienna, Austria. Environmental Research, 183, 109238.

Kok, A. (2019). Refining the CNOSSOS-EU calculation method for environmental noise. In INTERNOISE and NOISE-CON Congress and Conference Proceedings (Vol. 259, No. 8, pp. 1842-1849). Institute of Noise Control Engineering. Available online: http://www.seaacustica.es/fileadmin/INTERNOISE 2019/Fchrs/Proceedings/1418.pdf.

Kokkonen, J., Kontkanen, O., \& Maijala, P. P. (2016). CNOSSOS-EU Noise Model Implementation in Finland. Paper presented at the Baltic-Nordic Acoustic Meeting.

Kokkonen, J. (2018). CNOSSOS-EU noise model implementation in Finland and experience of it in 3rd END round. In Proceedings of Euronoise (pp. 27-31), Available online: http://www.euronoise2018.eu/docs/papers/207 Euronoise2018.pdf.

Kragh, J., Jonasson, H., Plovsing, B., \& Sarinen, A. (2006). User's guide Nord2000 Road. Available online: https://referencelaboratoriet.dk/metodeliste/2006 av117106-Users-Guide-Nord2000Road.pdf.

Kragh, J. (2009a). Nord2000 - New Nordic method for predicting road traffic noise. The Danish Road Directorate report \# 335. Available online: http://www.vejdirektoratet.dk/DA/viden og data/publikationer/Sider/default.aspx.

Kragh, J. (2011). Traffic noise prediction with Nord2000 - An update. Paper presented at the Proceedings of ACOUSTICS. Available online: https://pdfs.semanticscholar.org/db54/2015ae9c2a8463a8d7f908c3c8b497253f03.pdf. Large, D., \& Farmer, J. (2009). Broadband Cable Access Networks. The HFC Plant. Larsson, K. (2016). Updated road traffic noise emission models in Sweden. Paper presented at the INTER-NOISE and NOISE-CON Congress and Conference Proceedings. 
Maijala, P., \& Kontkanen, O. (2016). CNOSSOS-EU Sensitivity to Meteorological and Some Road Initial Value Changes. Paper presented at the INTER-NOISE and NOISE-CON Congress and Conference Proceedings.

Navrud, S. (2002). The state-of-the-art on economic valuation of noise. Final Report to European Commission DG Environment, 14. Available online at: https://pdfs.semanticscholar.org/f315/a2e9e41e9684d3ee41ea294b4c70c6c4cfbc.pdf.

Pamanikabud, P., \& Tansatcha, M. (2003). Geographical information system for traffic noise analysis and forecasting with the appearance of barriers. Environmental Modelling \& Software, 18(10), 959-973.

Peeters, B., \& Van Blokland, G. (2018). Correcting the CNOSSOS-EU road noise emission values. In Euronoise 2018-Conference, Available online: http://euronoise2018.eu/docs/papers/211 Euronoise2018.pdf.

Plovsing, B. (2006a). Nord2000. Comprehensive Outdoor Sound Propagation Model. Part 1: Propagation in an Atmosphere without Significant Refraction. Available online: http://www.magasbakony.hu/Val/Nord2000 homogeneous atmosphere Part 1.pdf.

Plovsing, B. (2006b). Nord2000. Comprehensive Outdoor Sound Propagation Model. Part 2: Propagation in an Atmosphere with Refraction. Report 1851/00. Retrieved from assets.madebydelta.com/docs/share/Akustik/Nord2000_Comprehensive_Outdoor_Sound_Pr opagation_Model-_-Part_2_Propagation_in_an_Atmosphere_with_Refraction.pdf.

Plovsing, B. (2014). Test Cases for Road Traffic Noise. DELTA Report Version 5 March 2014. Available online: https://referencelaboratoriet.dk/wp-content/uploads/2014/05/rl5-14 Test-cases-forroad-traffic-noise-Nord2000 Ver-5-March-2014.pdf.

PostGIS Development Group (2020). PostGIS - Spatial and geographic objects for PostgreSQL. Available online: $\underline{\text { https://postgis.net/. }}$

PostgreSQL Global Development Group (2020). PostgreSQL: The world's most advanced open-source relational database. Available online: https://www.postgresql.org/. 
Probst, W., \& Huber, B. (2010a). Accuracy and precision in traffic noise prediction. In Proceedings of conference Internoise (pp. 2170-2175), Available online: https://www.datakustik.com/fileadmin/user upload/e-Learning-Center/Papers-andPublications/2010 EAA TrafficNoisePrediction WP.pdf.

Probst, W. (2010b). New techniques in noise prediction. In Proceedings of 20th International Congress on Acoustics, ICA (pp. 23-27), Available online: https://www.acoustics.asn.au/conference proceedings/ICA2010/cdromICA2010/papers/p283.pdf.

Probst, W. (2019, September). Quality assurance for sound calculation software and its limitations. In INTER-NOISE and NOISE-CON Congress and Conference Proceedings (Vol. 259, No. 3, pp. 6555-6562). Institute of Noise Control Engineering. Available online: https://pdfs.semanticscholar.org/013e/ecda04174faa9e7b5a78099329b2d48ca77b.pdf.

QGIS Development Team (2020). QGIS. Available online: https://qgis.org/en/site/.

R Core Team (2020). R: A Language and Environment for Statistical Computing. Available online: https://www.r-project.org/.

RIVM (2019). Amendments for CNOSSOS-EU: Description of issues and proposed solutions. RIVM Letter Report \# 2019-0023. Available online: https://rivm.openrepository.com/bitstream/handle/10029/623095/20190023.pdf?sequence=3.

Salomons, E. M. (1997). Sound propagation in complex outdoor situations with a non-refracting atmosphere: a model based on analytical solutions for diffraction and reflection. Acta Acustica united with Acustica, 83(3), 436-454

Scholl, W., \& Wittstock, V. (2012). Does it matter whether single-number values of sound reduction indices are evaluated from third-octave band values or from octave band values?. Acta Acustica united with Acustica, 98(2), 354-360. 
SETRA-CERTU-LCPC, CSTB (1997). Bruit des infrastructures routieres, methode de calcul incluant les effets meteorologiques.

Sétra. (2009). Road noise prediction: Noise propagation computation method including meteorological effects (NMPB 2008). Retrieved from Technical Department of the Ministry of Ecology, Energy Sustainable Development and the Sea (France), Sétra: http://www.infratransports-materiaux.cerema.fr/IMG/pdf/US 0957-2A Road noise predictionDTRF.pdf.

SINTEF ICT (2020). SINTEF - Technology for a better society. Retrieved from https://www.sintef.no/en/.

Sørensen, M., Andersen, Z. J., Nordsborg, R. B., Jensen, S. S., Lillelund, K. G., Beelen, R., ... \& Raaschou-Nielsen, O. (2012). Road traffic noise and incident myocardial infarction: a prospective cohort study. PloS one, 7(6).

Sørensen, M., Lühdorf, P., Ketzel, M., Andersen, Z. J., Tjønneland, A., Overvad, K., \& RaaschouNielsen, O. (2014). Combined effects of road traffic noise and ambient air pollution in relation to risk for stroke?. Environmental research, 133, 49-55.

Steele, C. (2001). A critical review of some traffic noise prediction models. Applied Acoustics, 62(3), 271-287.

Tonne, C., Halonen, J. I., Beevers, S. D., Dajnak, D., Gulliver, J., Kelly, F. J., ... \& Anderson, H. R. (2016). Long-term traffic air and noise pollution in relation to mortality and hospital readmission among myocardial infarction survivors. International journal of hygiene and environmental health, 219(1), 72-78.

UK Department of Transport (1998). Calculation of road traffic noise (CoRTN). Available online: http://programmeofficers.co.uk/Preston/CoreDocuments/LCC389.pdf.

Van Blokland, G., \& Peeters, B. (2007). The noise emission model for European Road traffic, Deliverable 11 of the IMAGINE project, IMA55TR-060821-MP10.

Van Essen, H., Schroten, A., Otten, M., Sutter, D., Schreyer, C., Zandonella, R., Maibach, M., \& Doll, C. (2011). External Costs of Transport in Europe - Update Study for 2008. Available online: 
http://ecocalctest.ecotransit.org/CE Delft 4215 External Costs of Transport in Europe def.pdf.

689

690

691

692

693

694

695

696

697

698

699

700

701

702

703

704

705

706

707

708

709

710

711

712

Van Kempen, E., Casas, M., Pershagen, G., \& Foraster, M. (2018). WHO environmental noise guidelines for the European region: a systematic review of environmental noise and cardiovascular and metabolic effects: a summary. International journal of environmental research and public health, 15(2), 379.

Vergoed, T., \& van Leeuwen, H. J. (2018). Evaluation and Validation of the CNOSSOS calculation method in the Netherlands. In proceedings of Euronoise 2018, Available online: http://www.euronoise2018.eu/docs/papers/209 Euronoise2018.pdf.

World Health Organization (2019). Noise: Data and Statistics. Available online: http://www.euro.who.int/en/health-topics/environment-and-health/noise/data-andstatistics.

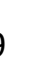

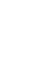

(1)

(1)

3

\section{4}

(1)

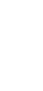



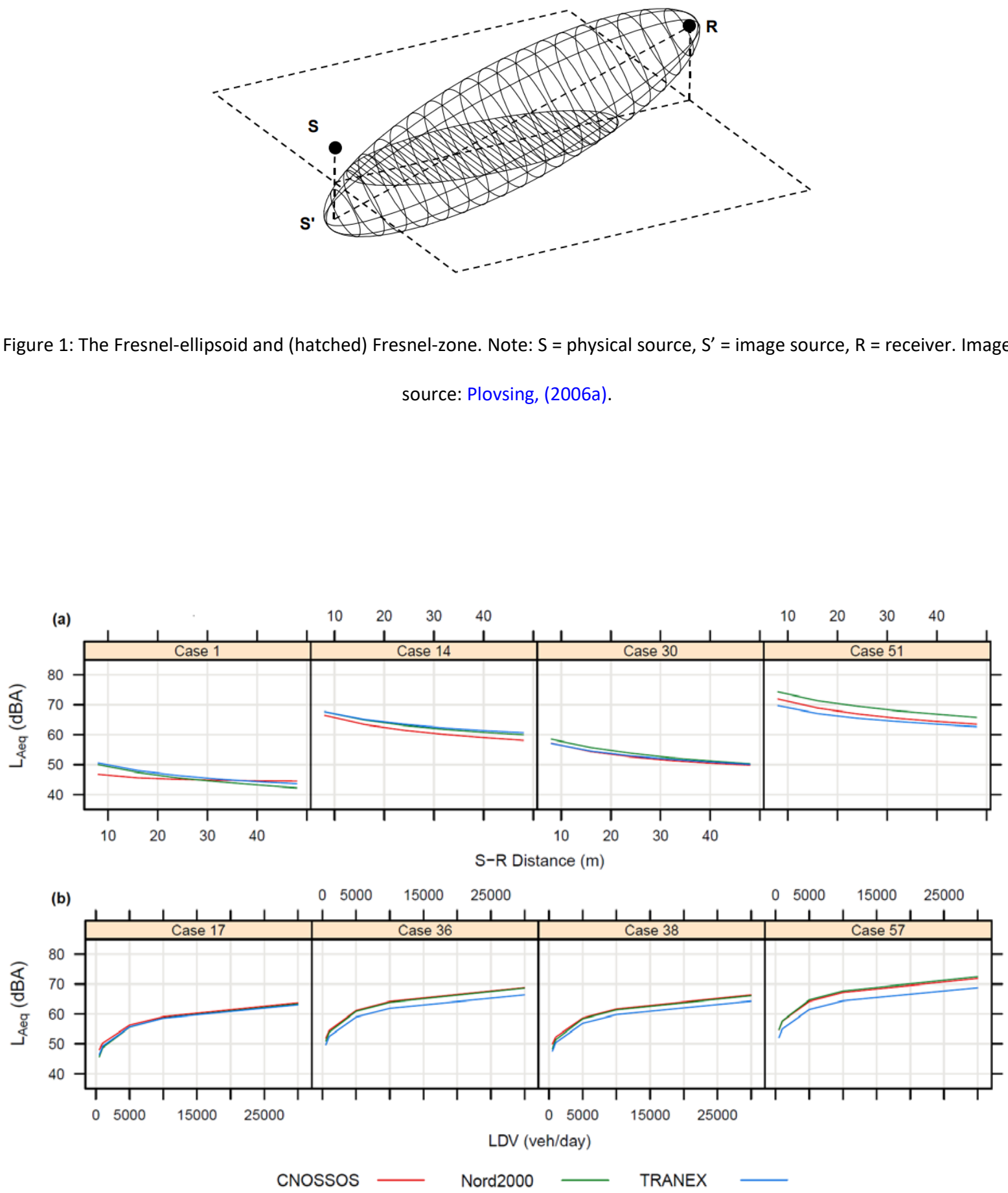

719 Figure 2: The comparison of predicted $\mathrm{L}_{\text {Aeq }}(\mathrm{dBA})$ of CNOSSOS, Nord2000 and TRANEX at varying (a) $\mathrm{S}-\mathrm{R}$ distance (m), and 720 (b) LDV (veh/day) for the selected test cases having similar geographical setting. The above results are for the "no building" scenario: Sound propagation over straight road with no reflections (buildings) or obstacles. Note: Case 1: LDV = 500 veh/day, speed $=40 \mathrm{~km} / \mathrm{h}$; Case 14: LDV and HDV $=10000$ veh/day, speed $=40 \mathrm{~km} / \mathrm{h}$; Case 30: LDV and HDV $=500$ veh/day, speed = $70 \mathrm{~km} / \mathrm{h}$; Case 51: LDV and HDV = 5000 veh/day, speed $=120 \mathrm{~km} / \mathrm{h}$; Case 17: S-R distance $=24 \mathrm{~m}$, speed = $40 \mathrm{~km} / \mathrm{h}$; Case 36 : distance $=24 \mathrm{~m}$, speed $=70 \mathrm{~km} / \mathrm{h}$; Case 38: distance $=40 \mathrm{~m}$, speed $=70 \mathrm{~km} / \mathrm{h} ;$ Case 57: distance $=40 \mathrm{~m}$, speed $=120 \mathrm{~km} / \mathrm{h}$. 


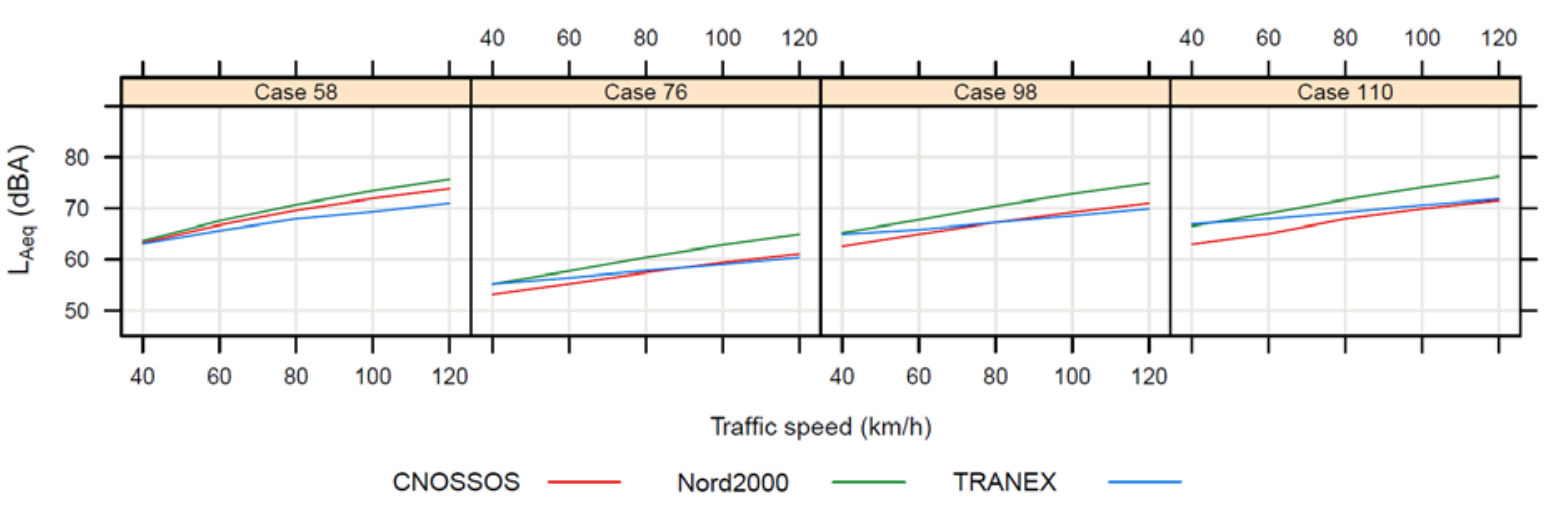

726 Figure 3: The comparison of predicted $\mathrm{L}_{\text {Aeq }}$ of CNOSSOS, Nord2000 and TRANEX at varying traffic speed for the selected test cases having similar geographical setting. The above results are for the "with building" scenario: Sound propagation over the straight road with building reflections. Note: Case 58: LDV = 10000 veh/day; Case 76: LDV and HDV = 500 veh/day; Case 98 and 110: LDV and HDV $=5000$ veh/day. The $S-R$ distance for all the above cases is $10 \mathrm{~m}$.
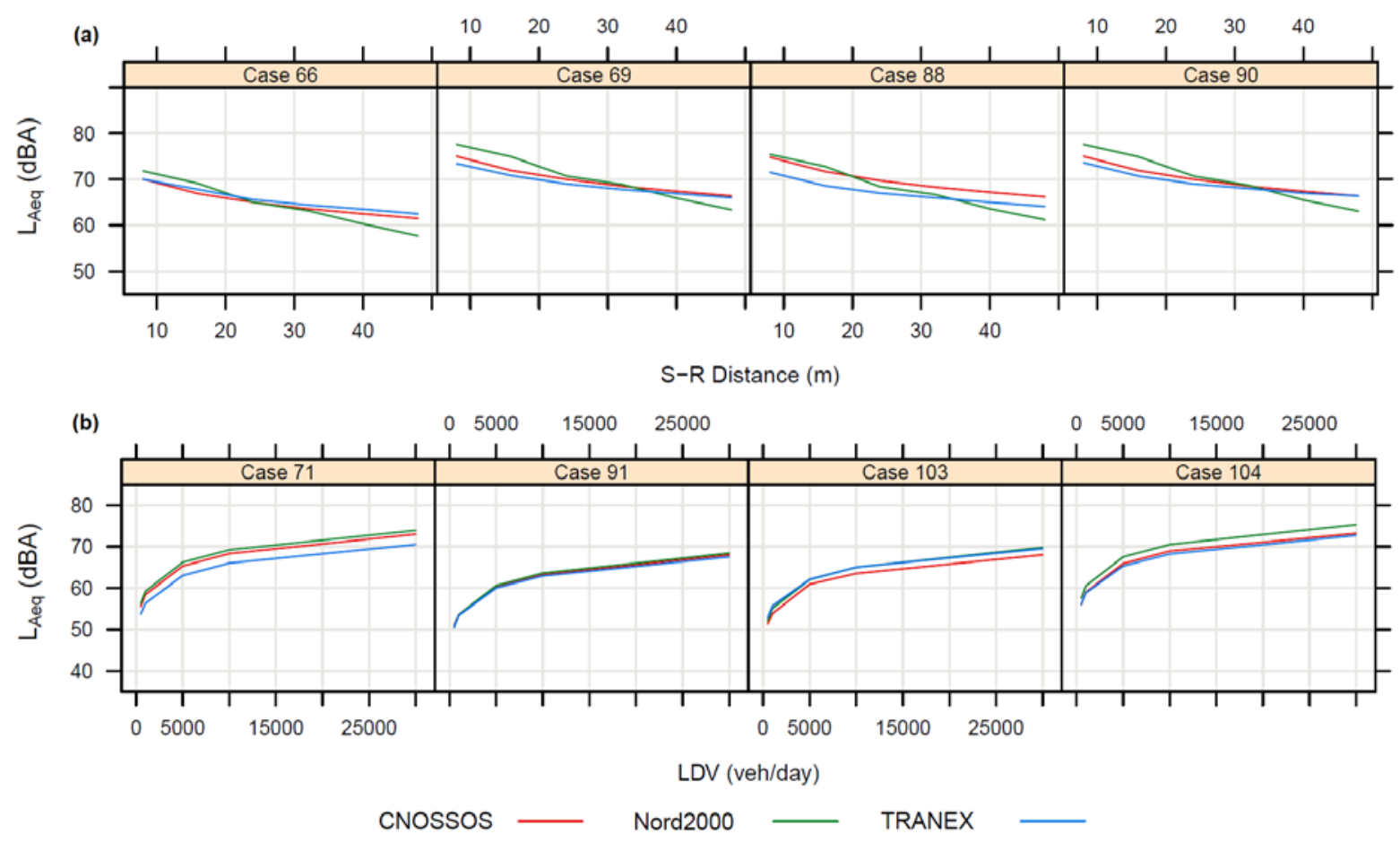

Figure 4: The comparison of predicted $\mathrm{L}_{\text {Aeq }}$ of CNOSSOS, Nord2000 and TRANEX at varying (a) $S-R$ distance (m), and (b) LDV

732 (veh/day) for the selected test cases having similar geographical setting. The above results are for the "with building" scenario: Sound propagation over straight road with building reflections. Note: Case 66: LDV and HDV = 10000 veh/day, speed $=70 \mathrm{~km} / \mathrm{h}$; Case 69: LDV and HDV $=10000$ veh/day, speed $=120 \mathrm{~km} / \mathrm{h}$; Case 88: LDV $=10000$ veh $/$ day, speed $=70$ km/h; Case 90: LDV and HDV $=10000$ veh $/$ day, speed $=120 \mathrm{~km} / \mathrm{h}$; Case 71: speed $=70 \mathrm{~km} / \mathrm{h} ;$ Case 91: $\mathrm{speed}=40 \mathrm{~km} / \mathrm{h} ;$ Case 103: speed $=40 \mathrm{~km} / \mathrm{h}$; Case 57: speed $=70 \mathrm{~km} / \mathrm{h}$. The S-R distance for test cases in (b) is $10 \mathrm{~m}$. 


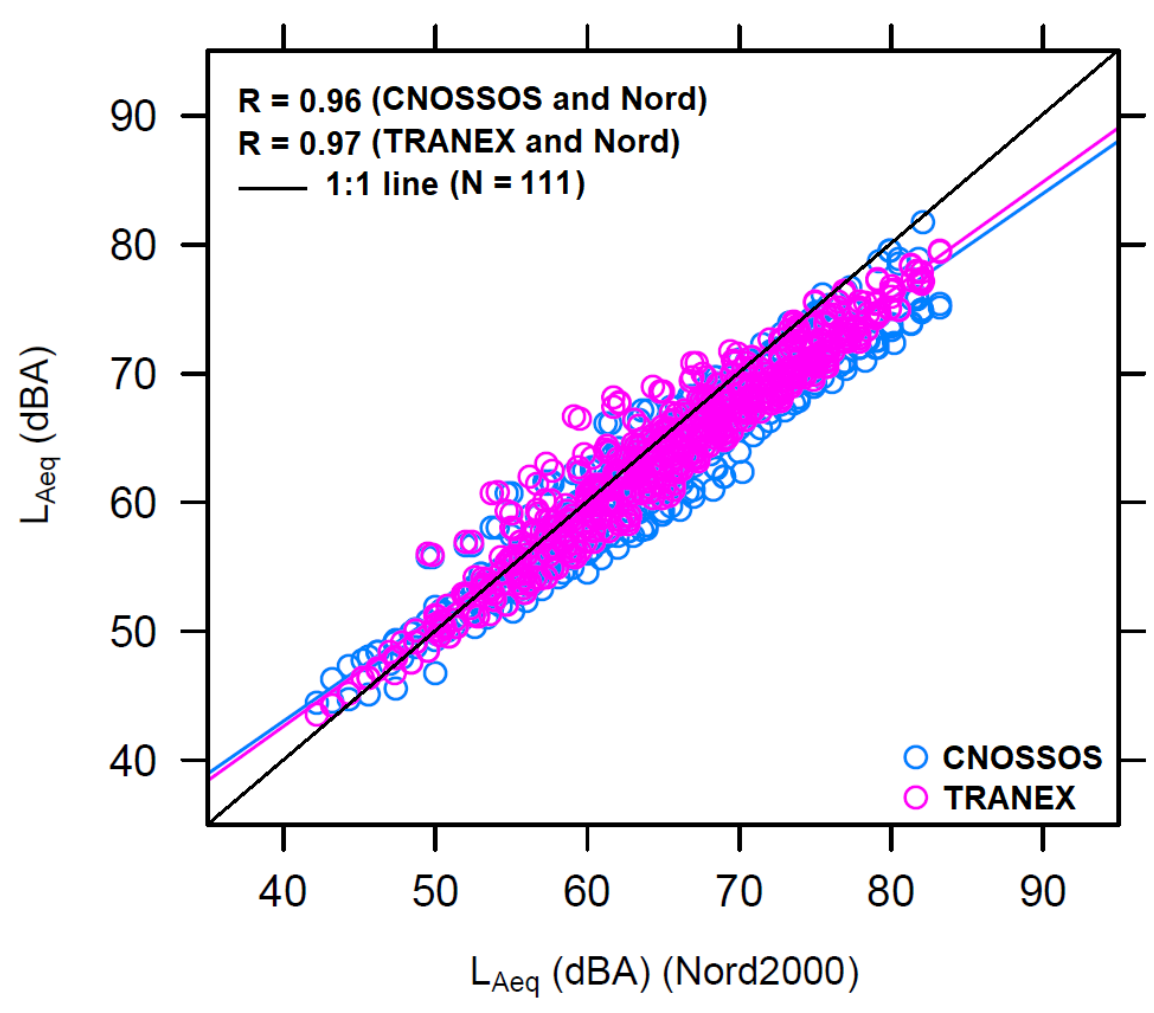

738 Figure 5: The comparison of simulated $\mathrm{L}_{\text {Aeq }}(\mathrm{dBA})$ of CNOSSOS and TRANEX with the Nord2000 corresponding values (all test

739 cases included, $\mathrm{N}=111$ ). The Pearson correlation coefficient $(\mathrm{R})$ and 1:1 line are also shown. 


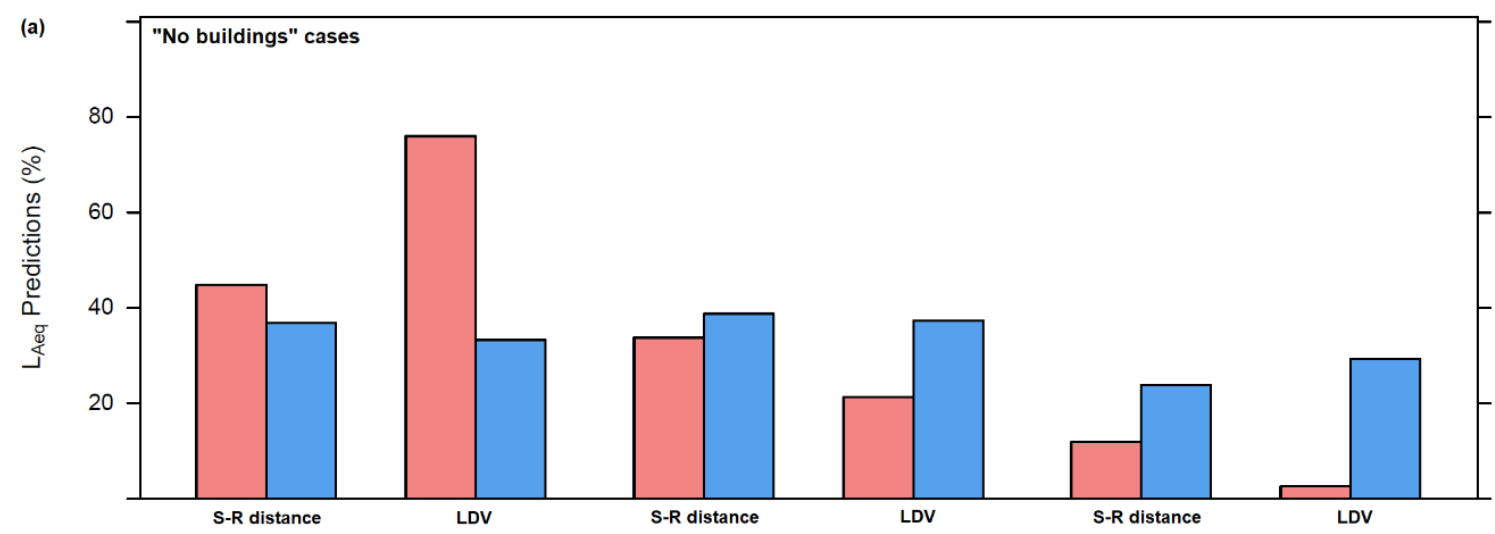

$0-1 \mathrm{dBA}$ difference

1-3 dBA difference

$3-5 \mathrm{dBA}$ difference

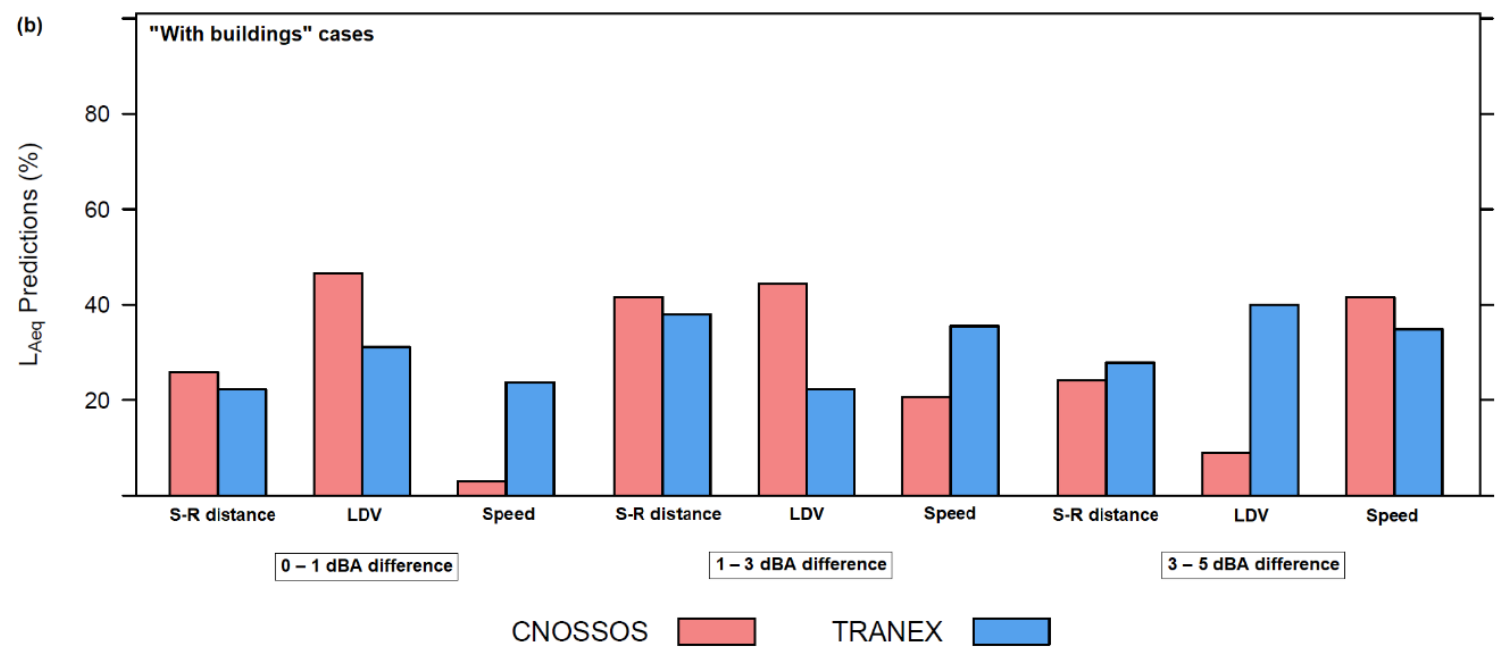

Figure 6: The comparison of predicted $L_{A e q}$ of CNOSSOS and TRANEX in the intervals $0-1 d B A, 1-3 d B A$ and $3-5 d B A$ of

742 the corresponding Nord2000 data for (a) "No building" cases: Sound propagation over the straight road with no building reflections or obstacles, and (b) "With building" cases: Sound propagation over the straight road with building reflections. The comparison (percentage of $\mathrm{L}_{\text {Aeq }}$ predictions) for "no building" scenario is based on varying (i) $\mathrm{S}-\mathrm{R}$ distance $(\mathrm{N}=42)$ and (ii) $L D V(N=15)$ test cases; the comparison for "with building" scenario is based on varying (i) $S-R$ distance ( $N=18)$, (ii) LDV ( $N=9)$ and (iii) Speed $(N=27)$ test cases. 
Plovsing, 2006b; Kephalopoulos et al., 2012; Garj and Maji, 2014; Gulliver et al., 2015).

\begin{tabular}{|c|c|c|c|}
\hline & Nord2000 & CNOSSOS & TRANEX \\
\hline Bands & $1 / 3$ Octave & Octave & $n / a$ \\
\hline Frequency range $(\mathrm{Hz})$ & $25-10000$ & $63-8000$ & $n / a$ \\
\hline $\begin{array}{l}\text { Reference speed } \\
(\mathrm{km} / \mathrm{h})\end{array}$ & 70 & 70 & 75 \\
\hline Speed range $(\mathrm{km} / \mathrm{h})$ & $30-130$ & $20-130$ & $20-130$ \\
\hline Road gradient (s) (\%) & $\begin{array}{l}\text { Correction of propulsion } \\
\text { noise }(s=0-20)\end{array}$ & $\begin{array}{l}\text { Correction of propulsion } \\
\text { noise }(s=-6 \text { to }+2 \text { ) }\end{array}$ & $\begin{array}{l}\text { Empirical correction } \\
(s=0-15)\end{array}$ \\
\hline $\begin{array}{l}\text { Reference } \\
\text { temperature }\left({ }^{\circ} \mathrm{C}\right)\end{array}$ & 20 & 20 & None \\
\hline Source height (m) & $0.01,0.30,0.75,3.5$ & 0.5 & 0.5 \\
\hline Rolling noise & $A_{R}+B_{R} \log \left(v / v_{\text {ref }}\right)$ & $A_{R}+B_{R} \log \left(v / v_{r e f}\right)$ & $n / a$ \\
\hline Propulsion noise & $A_{P}+B_{P}\left(v-v_{r e f} / v_{r e f}\right)$ & $A_{P}+B_{P}\left(v-v_{r e f} / v_{r e f}\right)$ & $\mathrm{n} / \mathrm{a}$ \\
\hline Noise emissions & $\begin{array}{l}\text { Sound power coefficients } \\
\left(A_{R}, B_{R} \text { and } A_{P}, B_{P}\right)\end{array}$ & $\begin{array}{l}\text { Sound power coefficients } \\
\left(A_{R}, B_{R} \text { and } A_{P}, B_{P}\right)\end{array}$ & $\begin{array}{l}\text { Emissions curves based on } \\
\text { an empirical approach }\end{array}$ \\
\hline Emissions database & {$[1]$} & The IMAGINE project [2] & $\mathrm{n} / \mathrm{a}$ \\
\hline $\begin{array}{l}\text { Correction for road } \\
\text { surfaces }\end{array}$ & Y & Y & $Y$ \\
\hline
\end{tabular}

757 


\begin{tabular}{|c|c|c|c|}
\hline & Nord2000 & CNOSSOS & TRANEX \\
\hline Bands & $1 / 3$ Octave & Octave & $n / a$ \\
\hline Frequency range $(\mathrm{Hz})$ & $25-10000$ & $63-8000$ & $n / a$ \\
\hline $\begin{array}{l}\text { Meteorological } \\
\text { conditions }\end{array}$ & $\begin{array}{l}25 \text { meteorological classes } \\
\text { based on logarithmic and } \\
\text { linear weather coefficients } \\
\text { (includes relative humidity) }\end{array}$ & $\begin{array}{l}\text { Homogeneous and } \\
\text { favourable conditions }\end{array}$ & $\mathrm{n} / \mathrm{a}$ \\
\hline $\begin{array}{l}\text { Maximum } S-R \text { path } \\
\text { length }(m)\end{array}$ & 1000 & 2000 & 1000 \\
\hline Receiver height $*(\mathrm{~m})$ & $1.5-4$ & $2-4$ & $2-4$ \\
\hline $\begin{array}{l}\text { Geometrical } \\
\text { divergence }\end{array}$ & $\begin{array}{l}10 \log \left(4 \pi d^{2}\right) \\
d=\mathrm{S}-\mathrm{R} \text { distance }\end{array}$ & $\begin{array}{l}20 \log (d)+11 \\
d=\mathrm{S}-\mathrm{R} \text { distance }\end{array}$ & $\begin{array}{l}-10 \log \left(d^{\prime} / 13.5\right) \\
d^{\prime}=\text { shortest slant } S-R \\
\text { distance }\end{array}$ \\
\hline Reflections & $\begin{array}{l}\text { Multiple reflections from } \\
\text { building façades as well as } \\
\text { reflections due to ground and } \\
\text { noise screens }\end{array}$ & $\begin{array}{l}\text { Multiple reflections from } \\
\text { building façades as well as } \\
\text { reflections due to ground } \\
\text { and noise screens }\end{array}$ & $\begin{array}{l}\text { Reflections from } \\
\text { building façades }\end{array}$ \\
\hline Ground effect & $\begin{array}{l}\text { Use of ray theory, Fresnel } \\
\text { zones, and Chien and Soroka } \\
\text { model [1]. Coherence factors } \\
\text { defined for effects from } \\
\text { scattering zones, frequency } \\
\text { band averaging, turbulence, } \\
\text { fluctuating refraction, surface } \\
\text { roughness etc. }\end{array}$ & $\begin{array}{l}\text { Use of mean ground plane, } \\
\text { acoustic characterisation of } \\
\text { ground, and several } \\
\text { atmospheric conditions. } \\
\text { Computed by interference } \\
\text { between the reflected and } \\
\text { the propagated sound }\end{array}$ & $\begin{array}{l}\text { Ground absorption } \\
\text { correction for (i) the } \\
\text { mean height of the } \\
\text { propagation (ii) the } \\
\text { different percentages of } \\
\text { the absorbent ground }\end{array}$ \\
\hline
\end{tabular}




\begin{tabular}{l|l|l|l} 
Diffraction effect & $\begin{array}{l}\text { Use of Hadden-Pierce ray [2] } \\
\text { and Salomons [3] approaches }\end{array}$ & Division of propagation path & Use of path difference \\
for single and multiple & w.r.t. point of diffraction. & diffracted ray paths \\
screens. The former approach & For each side, path & difference and ground & barrier correction using \\
(screens) as well as the & Joffects are calculated & the correction table \\
& with diffraction & &
\end{tabular}


781 Table 3: The simulation results (predicted $\mathrm{L}_{\text {Aeq }}, \mathrm{dBA}$ ) from CNOSSOS, Nord2000 (N2k) and TRANEX for the different

782 configurations (varying S - R distance etc.) Results for the randomly selected test cases (with and without building

783 scenarios) are shown here, see Supplementary Table S3 for complete simulation results, and Tables S1 and S2 for test

784 cases configurations. All predicted $\mathrm{L}_{\text {Aeq }}$ values and their differences are given in $\mathrm{dBA}$. Note: $|\Delta|=$ absolute difference.

\begin{tabular}{|c|c|c|c|c|c|}
\hline & \multicolumn{3}{|l|}{$L_{\text {Aeq }}(d B A)$} & \multicolumn{2}{|c|}{ Absolute difference (dBA) } \\
\hline & CNOSSOS & $\mathrm{N} 2 \mathrm{k}$ & TRANEX & $\left|\Delta_{N 2 k, \text { CNOSSOS }}\right|$ & $\left|\Delta_{N 2 k, T R A N E X}\right|$ \\
\hline \multicolumn{6}{|c|}{ No buildings } \\
\hline \multicolumn{6}{|c|}{ S - R Distance (m) } \\
\hline \multicolumn{6}{|c|}{ Case 1} \\
\hline 8 & 46.8 & 50.0 & 50.6 & 3.2 & 0.6 \\
\hline 16 & 45.6 & 47.4 & 48.0 & 1.8 & 0.6 \\
\hline 24 & 45.1 & 45.6 & 46.4 & 0.5 & 0.8 \\
\hline 32 & 44.8 & 44.3 & 45.2 & 0.5 & 0.9 \\
\hline 40 & 44.6 & 43.2 & 44.3 & 1.4 & 1.1 \\
\hline 48 & 44.5 & 42.2 & 43.6 & 2.3 & 1.4 \\
\hline
\end{tabular}

Case 13

\begin{tabular}{l|lllll}
\hline 8 & 63.5 & 64.7 & 64.7 & 1.2 & 0.0 \\
16 & 60.4 & 61.9 & 62.2 & 1.5 & 0.3 \\
24 & 58.6 & 60.1 & 60.6 & 1.5 & 0.5 \\
32 & 57.2 & 58.7 & 59.4 & 1.5 & 0.7 \\
40 & 56.1 & 57.8 & 58.5 & 1.7 & 0.7 \\
48 & 55.2 & 57.0 & 57.8 & 1.8 & 0.8 \\
\hline
\end{tabular}

Case 28

\begin{tabular}{l|lllll}
\hline 8 & 69.3 & 73.2 & 71.7 & 3.9 & 1.5 \\
16 & 66.2 & 70.3 & 69.1 & 4.1 & 1.2 \\
24 & 64.3 & 68.4 & 67.5 & 4.1 & 0.9 \\
32 & 62.9 & 67.0 & 66.4 & 4.1 & 0.6
\end{tabular}




\begin{tabular}{l|lllll}
40 & 61.8 & 66 & 65.5 & 4.2 & 0.5 \\
48 & 60.8 & 65.1 & 64.7 & 4.3 & 0.4 \\
\hline Case 39 & 61.9 & 62.1 & 58.4 & 0.2 & 3.7 \\
\hline 8 & 58.8 & 59.2 & 55.8 & 0.4 & 3.4 \\
16 & 57.0 & 57.3 & 54.2 & 0.3 & 3.1 \\
24 & 55.6 & 55.9 & 53.0 & 0.3 & 2.9 \\
32 & 54.6 & 54.7 & 52.1 & 0.1 & 2.6 \\
\hline 40 & 53.7 & 53.6 & 51.4 & 0.1 & 2.2 \\
\hline 48 & & & & & \\
\hline LDV (veh/day)
\end{tabular}

\begin{tabular}{|c|c|c|c|c|c|}
\hline \multicolumn{6}{|c|}{ Case 16} \\
\hline 500 & 49.4 & 47.4 & 48.0 & 2.0 & 0.6 \\
\hline 1000 & 51.7 & 50.4 & 50.8 & 1.3 & 0.4 \\
\hline 5000 & 58.1 & 57.4 & 57.3 & 0.7 & 0.1 \\
\hline 10000 & 61.0 & 60.4 & 60.2 & 0.6 & 0.2 \\
\hline 30000 & 65.7 & 65.2 & 64.7 & 0.5 & 0.5 \\
\hline \multicolumn{6}{|c|}{ Case 36} \\
\hline 500 & 51.9 & 50.9 & 49.6 & 1.0 & 1.3 \\
\hline 1000 & 54.5 & 53.9 & 52.5 & 0.6 & 1.4 \\
\hline 5000 & 61.2 & 60.9 & 59.0 & 0.3 & 1.9 \\
\hline 10000 & 64.2 & 63.9 & 61.9 & 0.3 & 2.0 \\
\hline 30000 & 68.9 & 68.7 & 66.4 & 0.2 & 2.3 \\
\hline \multicolumn{6}{|c|}{ Case 57} \\
\hline 500 & 54.6 & 54.7 & 52.1 & 0.1 & 2.6 \\
\hline 1000 & 57.6 & 57.7 & 55.0 & 0.1 & 2.7 \\
\hline 5000 & 64.2 & 64.7 & 61.5 & 0.5 & 3.2 \\
\hline 10000 & 67.2 & 67.7 & 64.4 & 0.5 & 3.3 \\
\hline 30000 & 71.9 & 72.5 & 68.8 & 0.6 & 3.7 \\
\hline
\end{tabular}




\begin{tabular}{|c|c|c|c|c|c|}
\hline \multicolumn{6}{|c|}{ With Buildings } \\
\hline \multicolumn{6}{|c|}{ Speed (km/h) } \\
\hline \multicolumn{6}{|c|}{ Case 58} \\
\hline 40 & 63.2 & 63.6 & 63.0 & 0.4 & 0.6 \\
\hline 60 & 66.7 & 67.5 & 65.6 & 0.8 & 1.9 \\
\hline 80 & 69.6 & 70.7 & 67.9 & 1.1 & 2.8 \\
\hline 100 & 71.9 & 73.4 & 69.3 & 1.5 & 4.1 \\
\hline 120 & 73.8 & 75.7 & 71.0 & 1.9 & 4.7 \\
\hline \multicolumn{6}{|c|}{ Case 75} \\
\hline 40 & 69.8 & 73.8 & 73.2 & 4.0 & 0.6 \\
\hline 60 & 70.6 & 75.7 & 73.9 & 5.1 & 1.8 \\
\hline 80 & 72.0 & 77.9 & 75.0 & 5.9 & 2.9 \\
\hline 100 & 73.4 & 80.0 & 76.0 & 6.6 & 4.0 \\
\hline 120 & 75.0 & 82 & 77.0 & 7.0 & 5.0 \\
\hline \multicolumn{6}{|c|}{ Case 99} \\
\hline 40 & 65.5 & 68.2 & 67.9 & 2.7 & 0.3 \\
\hline 60 & 68.0 & 70.7 & 68.9 & 2.7 & 1.8 \\
\hline 80 & 70.4 & 73.4 & 70.0 & 3.0 & 3.4 \\
\hline 100 & 72.4 & 75.8 & 70.6 & 3.4 & 5.2 \\
\hline 120 & 74.0 & 77.9 & 72.8 & 3.9 & 5.1 \\
\hline \multicolumn{6}{|c|}{ S - R Distance (m) } \\
\hline \multicolumn{6}{|c|}{ Case 62} \\
\hline 8 & 70.8 & 73.6 & 73.9 & 2.8 & 0.3 \\
\hline 16 & 67.6 & 70.8 & 71.3 & 3.2 & 0.5 \\
\hline 24 & 65.7 & 66.9 & 69.7 & 1.2 & 2.8 \\
\hline 32 & 64.4 & 65.0 & 68.6 & 0.6 & 3.6 \\
\hline 40 & 63.2 & 62.1 & 67.7 & 1.1 & 5.6 \\
\hline 48 & 62.3 & 59.5 & 66.5 & 2.8 & 7.0 \\
\hline
\end{tabular}




\begin{tabular}{|c|c|c|c|c|c|}
\hline \multicolumn{6}{|c|}{ Case 69} \\
\hline 8 & 75.0 & 77.6 & 73.4 & 2.6 & 4.2 \\
\hline 16 & 71.9 & 74.9 & 70.8 & 3.0 & 4.1 \\
\hline 24 & 70.0 & 70.7 & 69.0 & 0.7 & 1.7 \\
\hline 32 & 68.5 & 68.9 & 67.8 & 0.4 & 1.1 \\
\hline 40 & 67.4 & 65.9 & 66.9 & 1.5 & 1.0 \\
\hline 48 & 66.4 & 63.4 & 66.0 & 3.0 & 2.6 \\
\hline \multicolumn{6}{|c|}{ Case 88} \\
\hline 8 & 74.8 & 75.4 & 71.5 & 0.6 & 3.9 \\
\hline 16 & 71.7 & 72.8 & 68.6 & 1.1 & 4.2 \\
\hline 24 & 69.7 & 68.4 & 67.0 & 1.3 & 1.4 \\
\hline 32 & 68.3 & 66.7 & 66.0 & 1.6 & 0.7 \\
\hline 40 & 67.2 & 63.6 & 65.0 & 3.6 & 1.4 \\
\hline 48 & 66.2 & 61.2 & 64.1 & 5.0 & 2.9 \\
\hline
\end{tabular}

\begin{tabular}{|c|c|c|c|c|c|}
\hline Case 70 & & & & & \\
\hline 500 & 51.0 & 50.6 & 50.3 & 0.4 & 0.3 \\
\hline 1000 & 53.6 & 53.6 & 53.2 & 0.0 & 0.4 \\
\hline 5000 & 60.2 & 60.6 & 59.8 & 0.4 & 0.8 \\
\hline 10000 & 63.2 & 63.6 & 62.8 & 0.4 & 0.8 \\
\hline 30000 & 67.9 & 68.4 & 67.4 & 0.5 & 1.0 \\
\hline \multicolumn{6}{|l|}{ Case 91} \\
\hline 500 & 51.0 & 50.6 & 50.5 & 0.4 & 0.1 \\
\hline 1000 & 53.6 & 53.6 & 53.4 & 0.0 & 0.2 \\
\hline 5000 & 60.2 & 60.6 & 60.0 & 0.4 & 0.6 \\
\hline 10000 & 63.2 & 63.6 & 62.9 & 0.4 & 0.7 \\
\hline 30000 & 68.0 & 68.4 & 67.5 & 0.4 & 0.9 \\
\hline \multicolumn{6}{|c|}{ Case 105} \\
\hline
\end{tabular}




\begin{tabular}{l|lllll}
\hline 500 & 61.0 & 64.1 & 60.8 & 3.1 & 3.3 \\
\cline { 2 - 6 } 5000 & 64.0 & 67.1 & 63.4 & 3.1 & 3.7 \\
\multirow{2}{*}{5000} & 71.0 & 74.1 & 69.9 & 3.1 & 4.2 \\
30000 & 74.0 & 77.1 & 72.8 & 3.1 & 4.3 \\
\hline
\end{tabular}

785 